\title{
New research findings on non-proportional low cycle fatigue
}

\author{
Anghel Cernescu ${ }^{1,2}$, Rhys Pullin ${ }^{2}$ \\ ${ }^{2}$ Department of Mechanical Engineering, Cardiff University, United Kingdom
}

\begin{abstract}
One of the challenges regarding multiaxial fatigue damage predictions is non-proportional loading. Relevant studies have shown that these multiaxial loadings cause significant additional hardening and reduction in durability due to non-proportionality. Fatigue life predictions due to non-proportional loadings are based on an equivalent nonproportional strain range that considers a material constant related to additional hardening and a non-proportionality factor. In this paper an analysis of the non-proportional factor for three multiaxial loadings forming a square in $\gamma / \sqrt{ } 3-\varepsilon$ coordinates is carried out. One of the observations revealed by this analysis is the sensitivity of the non-proportional factor to variable shear strain rate.
\end{abstract}

\section{Introduction}

The stress or strain state in a material point is defined as a multiaxial state. This multiaxiality is influenced by the external load, geometry, residual stress, etc. The problem of multiaxiality becomes more complicated when the stress/strain components vary over time and even more when they vary in an independent manner or at different frequencies. The mode of time variation of the stress/strain state components introduces effects that complicate the prediction of fatigue damage. Multiaxial loadings are non-proportional if the principal directions and the corresponding principal stresses/strains change over a loading cycle. Such loadings are very common in the operation of mechanical components, can be complex as a variation over time and it is difficult to quantify their effect on the fatigue life. However, considerable efforts have been made in this direction for development of methods, algorithms and/or criteria for analysing complex stress/strains histories and, respectively, the assessment of non-proportional effects on fatigue damage. Based on an experimental study of low-cycle fatigue tests under combined axial and torsional strains with different phase angles, Kanazawa, Brown and Miller, [1-3], highlighted a number of significant issues. These can be summarized as: a) during out-of-phase biaxial tests, fatigue cracks initiate on the plane of maximum shear strain; b) the fatigue life is governed by the shear strain range and the amplitude of normal strain on the plane of maximum shear strain; c) the out-of-phase loading condition with phase angle of $90^{\circ}$ and strain ratio $\lambda=\gamma_{\mathrm{a}} / \varepsilon_{\mathrm{a}}=1.5$ (where $\gamma_{\mathrm{a}}$ is the amplitude of shear strain and $\varepsilon_{\mathrm{a}}$ is the amplitude of normal strain) gave the lowest lifetime. Another 
important observation of their studies is the additional hardening phenomenon due to the rotation of the principal directions during a cycle. Considering this phenomenon quantified through a parameter, it was possible to correlate out-of-phase data in a single stress-strain curve. Very important contributions were made by Socie and his collaborators who started by experimentally highlighting two cracking modes of materials (Mode II - shear cracking and Mode I - tensile-cracking) that need to be considered in lifetime predictions of components subjected to multiaxial fatigue, $[4,5]$. Itoh et al, $[6,7]$, explain the rotation of principal directions by the degree of non-proportionality that is found to be maximum for a load which in $\gamma / \sqrt{3}-\varepsilon$ coordinates forms a square. Also, an equivalent non-proportional strain range is defined which correlates the non-proportional experimental data. This strain range includes a material constant that describes the additional cyclic hardening under $90^{\circ}$ out-ofphase and a factor that expresses the severity of non-proportional loading obtained directly from the strain history. Non-proportional multiaxial loadings result in the initiation of large number of microcracks compared to proportional loadings. These microcracks propagate in different directions due to the rotation of the principal directions and the activation of multiple slip systems. At the same time, the large number of microcracks initiated is responsible for reducing the fatigue life, [8]. Shamsaei et al., [9, 10], found that the fatigue life of 1050 QT steel without additional non-proportional hardening is more sensitive to multiaxial non-proportional loadings than 304L stainless steel which shows significant nonproportional cyclic hardening. This observation supports the idea that additional nonproportional hardening is not the only effect responsible for reducing the fatigue life. An alternative method for evaluation the non-proportional loading effects was proposed by Freitas et al., [11]. They evaluate the effective shear stress/strain amplitude throughout a complex loading based on the geometric characteristics of a minimum ellipse embodying the multiaxial load path. Recent studies suggest a link between the microstructure of the material and the non-proportional loading effects. The non-proportional hardening may be related to stacking faults and dislocation structures, which have different forms produced by different loading paths, [12]. A new non-proportionality damage factor based on accumulative path length traversed within half cycle is proposed in [13] and [14]. This factor can vary from zero for proportional load to 1 for a semi-circular load. These studies are focused on the overall correlation of non-proportional experimental data through an equivalent parameter that includes a factor corresponding to additional cyclic hardening and respectively a factor corresponding to the loading path.

Based on analysis of low cycle multiaxial fatigue data, a slight inconsistency was observed between experimental data and correlations used for non-proportional loadings which describes a square in $\gamma / \sqrt{ } 3-\varepsilon$ coordinates. Also, in most cases these loadings determine the lowest fatigue life, even lower than non-proportional $90^{\circ}$ out-of-phase loadings.

An analysis of the non-proportionality factor for square loadings is carried out in this paper. Thus, three non-proportional loadings are proposed in the paper which in $\gamma / \sqrt{ } 3-\varepsilon$ coordinates describe a square. For these loadings the non-proportional load factor and implicitly their effect on fatigue damage has been analysed.

\section{Material and methods}

The analysis performed in this paper has as a starting point three sets of low cycle multiaxial fatigue data, where the square non-proportional loadings have been considered among others. These experimental data include tests conducted by Socie [5], Itoh et al. [6] and Nobah et al. [15].

The experimental analysis by Itoh et al. reveals a maximum degree of non-proportionality in the case of square loading that determined the lowest fatigue life. Continuous loading path similar to the square loading are more damaging compared to discontinuous loading path. 
For Nobah et al. tests, the same axial and shear strain amplitudes used for $90^{\circ}$ out-of-phase and square loadings gave lower fatigue lives in the case of square loading. The same trend is maintained for Socie's tests. These experimental evidences indicates the need for a detailed analysis of non-proportional square loadings.

On the other hand, the current approach uses an equivalent non-proportional strain range to correlate the non-proportional fatigue data with the proportional ones. This parameter is defined by the following relationship:

$$
\Delta \varepsilon_{N P}=\left(1+\alpha \cdot f_{N P}\right) \cdot \Delta \varepsilon_{I}
$$

where $\Delta \varepsilon_{\mathrm{I}}$ is the principal strain range, $\alpha$ is a parameter related to the additional hardening under nonproportional loading and is defined as the ratio of stress amplitudę in $90^{\circ}$ out-ofphase loading to that from in-phase loading. The nonproportionality factor, $f_{N P}$, express the severity of nonproportional loading and is obtained directly from the strain history.

Practically, the correlation of non-proportional and proportional fatigue data depends on the product of $\alpha \cdot f_{\mathrm{NP}}$.

Considering that $\alpha$ is a material constant experimentally determined under the same conditions for each tested materials, attention should be directed to the non-proportional load factor. Also, taking into account the fact that there are materials that do not exhibit additional non-proportional hardening but they are sensitive to non-proportional fatigue loadings, the analysis in this paper focuses on the non-proportional load factor for square loadings.

Therefore, three non-proportional loadings are proposed in the paper which in $\gamma / \sqrt{ } 3-\varepsilon$ coordinates describe a square. The three loadings are shown in Figs. $1-3$.

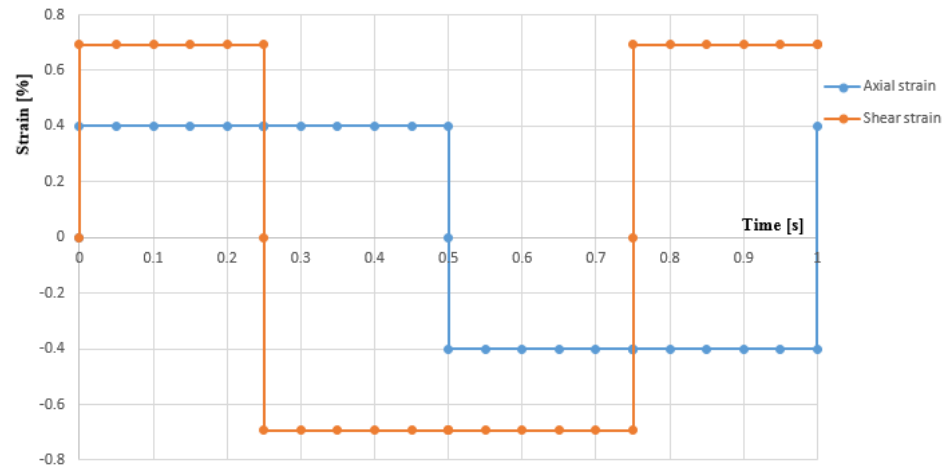

Fig. 1. Non-proportional load path 1

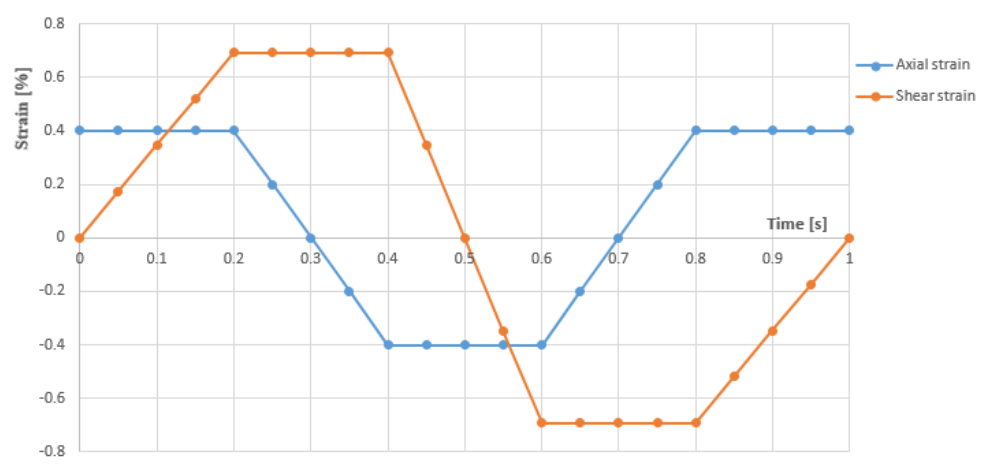

Fig. 2. Non-proportional load path 2 


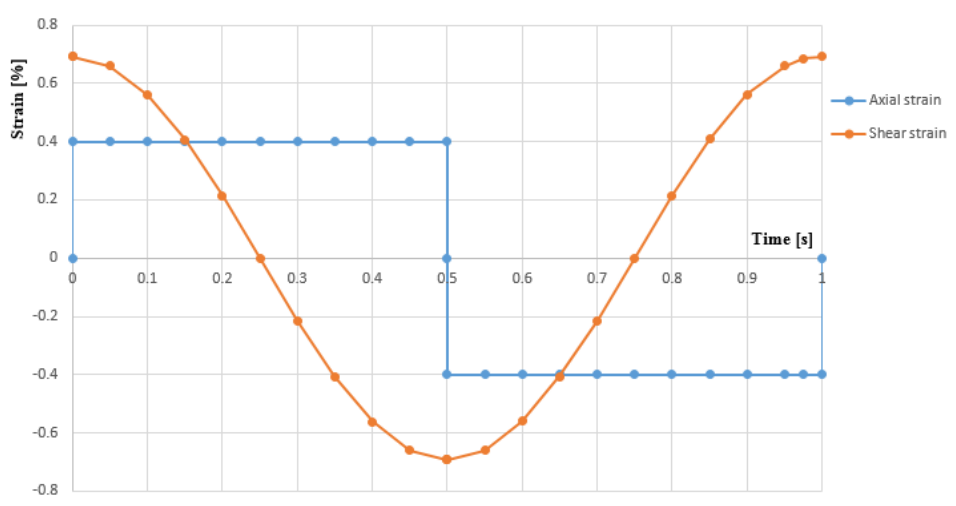

Fig. 3. Non-proportional load path 3

The three loadings, although having different variations of axial and shear strains, in $\gamma / \sqrt{ } 3$ $-\varepsilon$ coordinates they describe a square with the same limits, Fig. 4.

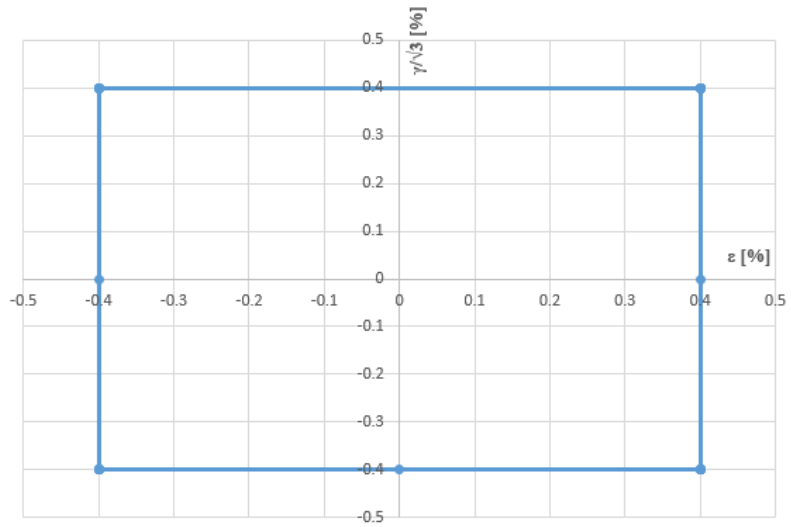

Fig. 4. The square loading described by the three non-proportional loadings

Two techniques have been used in this paper to analyse the non-proportionality factor for the three loadings. On the one hand, the method developed by Itoh et all. [6], based on the rotation of the principal strain directions, was used to analyse the severity of each nonproportional loading. The second method, developed by Mei and Dong, [13], based on the accumulative Moment of Load Path (MLP) concept was applied for analysing the dimensionless non-proportionality induced damage factor, $\mathrm{g}_{\mathrm{NP}}$.

According to Itoh's approach, the severity of non-proportional low cycle fatigue is calculated by measuring the rotation of the maximum principal strain direction and the strain amplitude after rotation, fig. 5. This severity is expressed by a non-proportional factor, $f_{N P}$, defined as integral form:

$$
f_{N P}=\frac{1.57}{T \cdot \varepsilon_{I, \max }} \int_{0}^{T}\left(|\sin \xi(t)| \cdot \varepsilon_{I}(t)\right) d t
$$

where $\varepsilon_{\mathrm{I}}(\mathrm{t})$ is the maximum absolute value of principal strain at time $t$ and given by equation (3), $\varepsilon_{I, \max }$ is the maximum value that principal strain records during the loading path, $T$ is the period of a cycle and $\xi(t)$ is the angle between $\varepsilon_{I, m a x}$ and $\varepsilon_{I}(t)$. The constant 1.57 is chosen to make $f_{N P}$ unity for $90^{\circ}$ out-of-phase loading.

The Mei and Dong approach is based on a normalized integral form of the load path nonproportionality induced fatigue damage, Fig. 6, given by the following relationship : 


$$
g_{N P}=\frac{D_{N P}}{D_{\max }}=\frac{\int_{A B} r^{\prime}|\sin \theta| d s^{\prime}}{2 R^{2}}
$$

where $D_{N P}$ is the total load path non-proportionality induced fatigue damage, $D_{\max }$ is the maximum possible non-proportional fatigue damage induced by a semi-circular load path with radius $\mathrm{R}$.

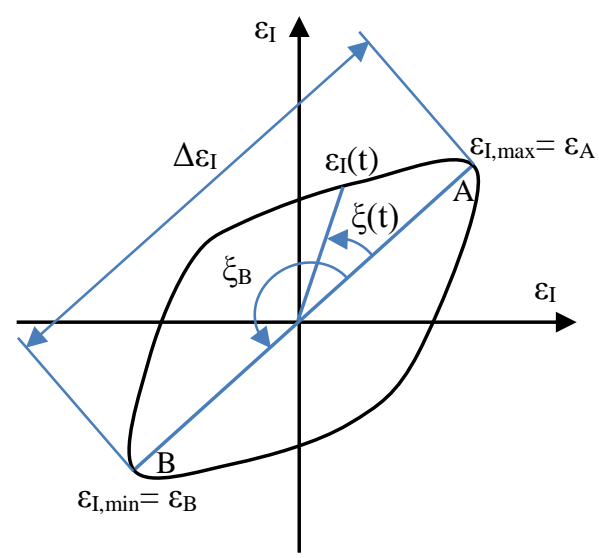

Fig. 5. The load path representation in $\varepsilon_{I^{-}}$ plane, according to Itoh's method

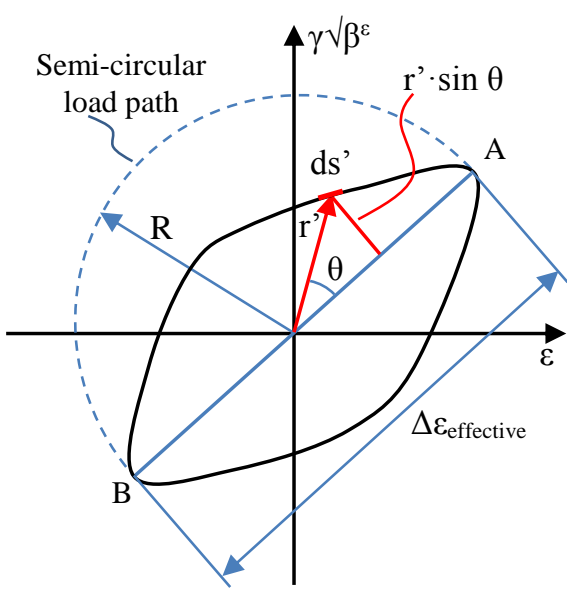

Fig. 6. The load path representation in $\varepsilon-\gamma \sqrt{ } \beta^{\varepsilon}$ plane, according to Mei and Dong

The term $\sqrt{ } \beta^{\varepsilon}$ is a fatigue equivalency parameter between pure cyclic tensile strain and pure shear strain. For this analysis $\beta^{\varepsilon}=1 / 3$.

Two evidences are clear based on the definitions of the two non-proportional factors. The dimensionless non-proportional factor $g_{N P}$ is calculated with respect to $\varepsilon-\gamma \sqrt{ } \beta^{\varepsilon}$ strain plane while Itoh et al.'s non-proportional factor $f_{N P}$ is defined with respect to a polar coordinate based maximum principal strain plane as a function of its direction (angle). Also, the nonproportional factor $g_{N P}$ is defined with respect to the reference semi-circular load path wich corresponds to conditions yielding the maximum possible damage among all paths between any two positions forming one half cycle in $\varepsilon-\gamma \sqrt{ } \beta^{\varepsilon}$ plane, while Itoh's et al.'s factor is calculated with respect to the maximum principal strain within a loading event.

\section{Results and discussion}

For each loading path, the variation of the principal strain according to Itoh's method was determined, Fig. 7, as follows:

$$
\varepsilon_{1,3}(t)=\frac{1-v}{2} \varepsilon \pm \frac{1}{2} \sqrt{(1+v)^{2} \varepsilon^{2}+\gamma^{2}}
$$

where $\varepsilon$ is the applied axial strain, $\gamma$ is the applied shear strain and $v$ is the Poisson's ratio.

$$
\begin{gathered}
\varepsilon_{I}(t)=\varepsilon_{1} \text { if } \varepsilon_{1}(t) \geq\left|\varepsilon_{3}(t)\right| \\
\varepsilon_{I}(t)=\varepsilon_{3} \text { if }\left|\varepsilon_{1}(t)\right|<\varepsilon_{3}(t)
\end{gathered}
$$




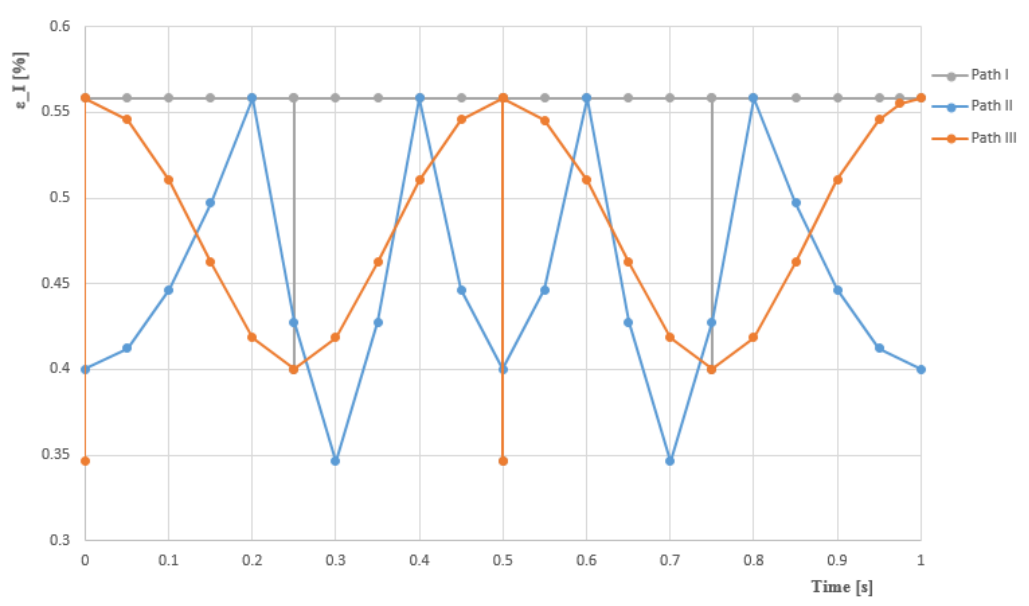

Fig. 7. The principal strain variation for the three loadings

The principal strain differs significantly from one loading to another. From a constant value corresponding to Path I, where changes of principal strain are recorded only in the moments of changing direction for axial and respectively shear strain, to a sinusoidal variation strongly influenced by the variation of the shear strain, in the case of load Path III.

For the determination of the angle between the principal directions and the calculation of the non-proportional factor, the three variations of the principal strains are represented in polar figure, similar to Fig. 5. Thus, the polar figures of the principal strain variations are given in Fig. 8 .

Applying the Mei and Dong method, mainly involves the computation of the $r^{\prime} \cdot \sin \theta$ term and integrating over the loading path. For the three analysed load paths, the variations of $r^{\prime} \cdot \sin \theta$ term during a loading cycle are shown in Fig. 9.

Table 1 gives the values of the non-proportional factor for the analysed loadings, based on the two methods used.

The model proposed by Kanazawa et al. [2], was used in this paper to estimate the equivalent stress amplitude for a given equivalent strain amplitude, for the three analysed loading paths. This model incorporates the additional non-proportional hardening in the cyclic behaviour and is defined as:

$$
\frac{\Delta \bar{\sigma}}{2}=K_{p}^{\prime}(1+\alpha F)\left(\frac{\Delta \bar{\varepsilon}_{p}}{2}\right)^{n_{p}^{\prime}}
$$

where $\Delta \bar{\sigma} / 2$ is the equivalent stress amplitude, $\Delta \bar{\varepsilon}_{p} / 2$ is the equivalent plastic strain amplitude, $K_{p}^{\prime}$ is the proportional (uniaxial) cyclic strength coefficient, $n_{p}^{\prime}$ is the proportional (uniaxial) cyclic strength exponent, $\alpha$ is the additional non-proportional hardening and $\mathrm{F}$ is the non-proportional load factor.

The model was applied on two materials analysed by Shamsaei et al. [10], one of which does not show additional non-proportional hardening (a medium carbon 1050 steel in quenched and tempered condition), while the other exhibit additional non-proportional hardening (a 304L stainless steel). The used properties of these materials are given in Table 2. 


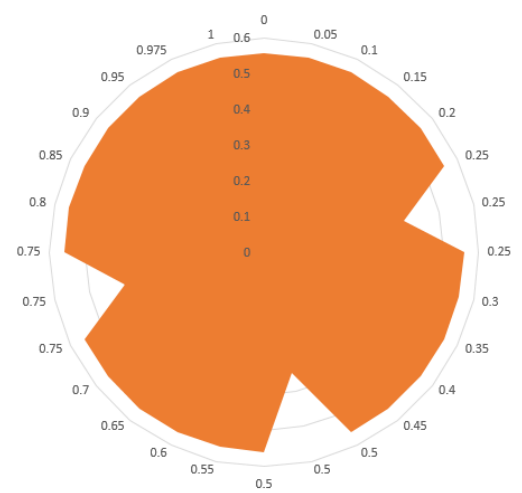

a)

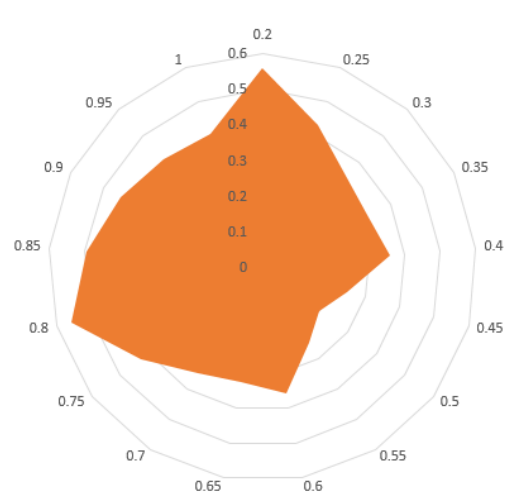

b)

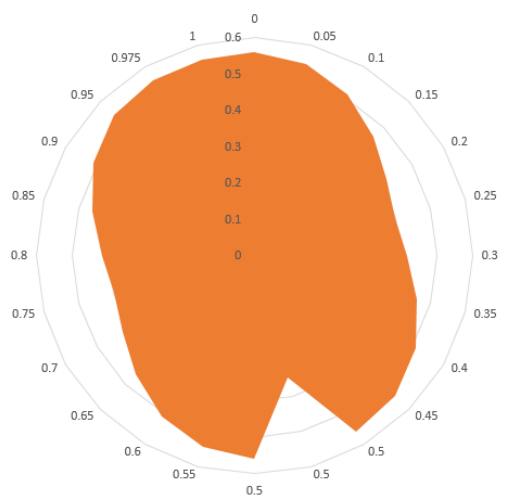

c)

Fig. 8. The polar figures corresponding to the three loadings: a) Path I; b) Path II; c) Path III

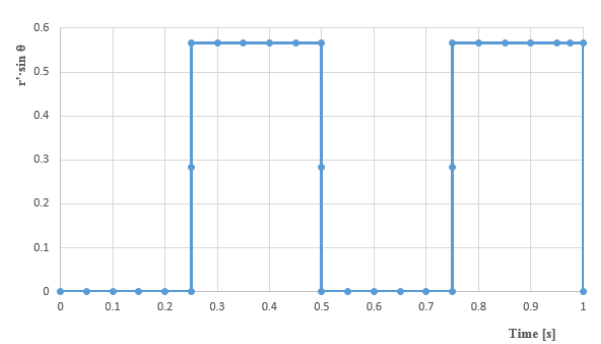

a)

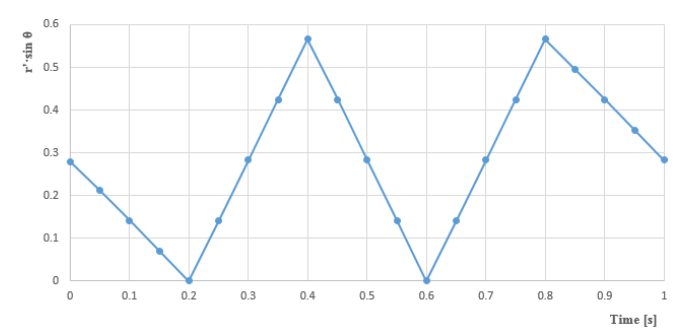

b)

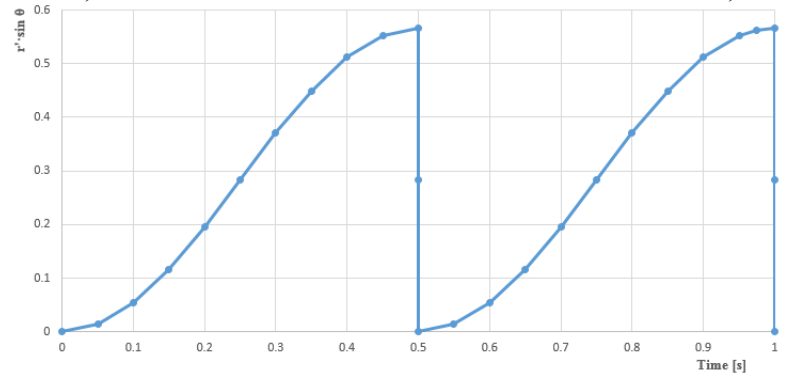

c)

Fig. 9. The variation of non-proportionality induced fatigue damage: a) Path I; b) Path II; c) Path III 
Table 1. The non-proportional factor for square loadings

\begin{tabular}{|c|c|c|}
\hline \multirow{2}{*}{ Load path } & \multicolumn{2}{|c|}{ Non-proportional factor } \\
\cline { 2 - 3 } & $\begin{array}{c}\text { Itoh method } \\
\mathbf{f}_{\mathbf{N P}}\end{array}$ & $\begin{array}{c}\text { Mei and Dong method } \\
\mathbf{g N P}_{\mathbf{N P}}\end{array}$ \\
\hline Path I & 0.99 & 0.442 \\
\hline Path II & 0.781 & 0.442 \\
\hline Path III & 0.89 & 0.524 \\
\hline
\end{tabular}

Table 2. The monotonic and in-phase cyclic properties of the two steels used in the analysis

\begin{tabular}{|c|c|c|}
\hline Mechanical properties & 1050 QT & 304L stainless steel \\
\hline Modulus of elasticity, $\mathrm{E}(\mathrm{MPa}$ & 203000 & 195000 \\
\hline Yield strength, $\sigma_{\mathrm{y}}(\mathrm{MPa})$ & 1009 & 208 \\
\hline Ultimate strength, $\sigma_{\mathrm{u}}(\mathrm{MPa})$ & 1164 & 585 \\
\hline Strength coefficient, $\mathrm{K}(\mathrm{MPa}$ & 1461 & 680 \\
\hline Strain hardening exponent, $\mathrm{n}$ & 0.060 & 0.214 \\
\hline In-phase cyclic properties & & 2841 \\
\hline Cyclic strength coefficient, $\overline{K^{\prime}}(\mathrm{MPa})$ & 1558 & 0.371 \\
\hline Cyclic strain hardening exponent, $\bar{n}^{\prime}$ & 0.123 & 0.55 \\
\hline Non-proportional hardening coefficient, $\alpha$ & -0.04 & \\
\hline
\end{tabular}

Considering the materials loaded with the three non-proportional square loadings with an equivalent plastic strain amplitude of 0.00566 , Figures 10 and 11 present the estimated equivalent stress amplitudes.

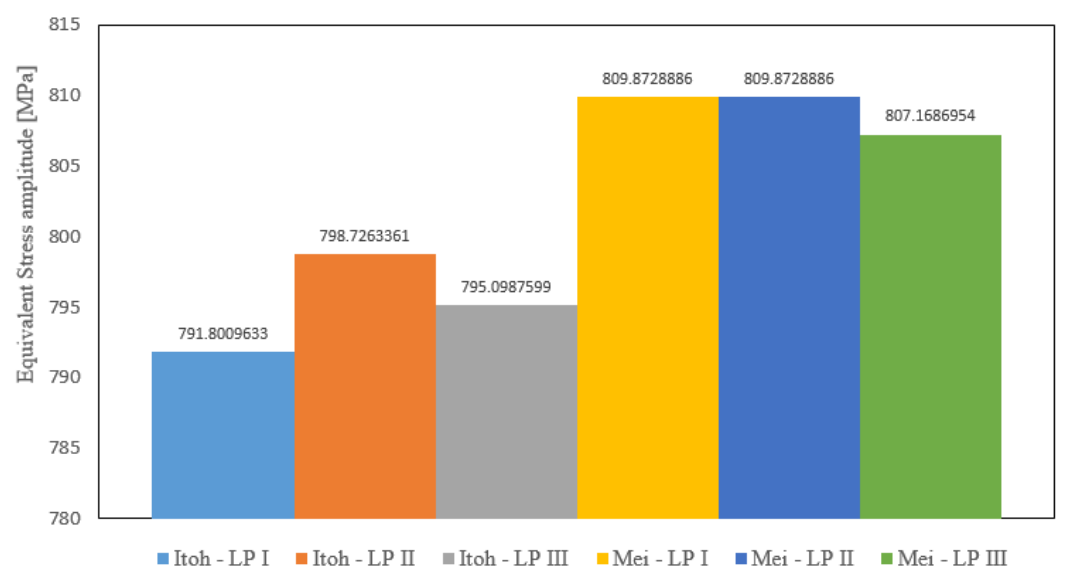

Fig. 10. The estimated equivalent stress amplitude for 1050 QT steel (LP - loading path) 


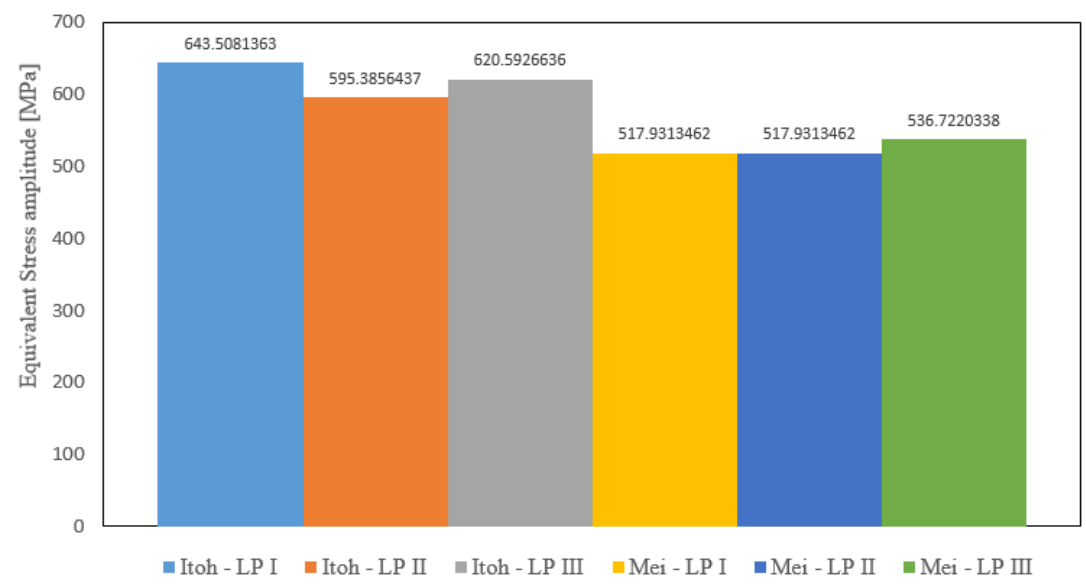

Fig. 11. The estimated equivalent stress amplitude for 304L stainless steel (LP - loading path)

A first observation that supports the Shamsaei findings on 1050 QT steel is the low sensitivity of the stress response to the loading path. In addition, the non-proportional load factor according to Mei and Dong method indicates an equivalent stress amplitude of only $1.4 \%$ higher than the Itoh method. Instead, for $304 \mathrm{~L}$ stainless steel, the Itoh method estimate an equivalent stress amplitude of $15 \%$ higher than the Mei and Dong method. Also, in the case of Path I the difference is $24 \%$ for Itoh method compared to Mei and Dong method.

Although the three loadings form the same square in $\gamma / \sqrt{3}-\varepsilon$ coordinates, the variation law of axial and shear strains influences the severity of the non-proportional loading. Moreover, the severity of non-proportional loading proves to be more sensitive at variable shear strain rates.

The loading Path I presents two important features, primarily, maintaining under constant shear strain for a half-cycle over which axial strain overlaps could have effects on ductility and implicitly on low cycle fatigue life. In a study conducted by Shenguyan Ji et all., [16], it is reported that the ductility decrease gradually with the increase of the shear pre-strain, instead the low cycle fatigue life is divided in three stages. Gradually increasing of the shear pre-strain determines a first stage with monotonically decreasing of fatigue life, followed by a second stage with fatigue life monotonically increasing and a third stage with decreasing the fatigue life. Depending on the amplitude of the shear pre-strain, one of the three stages in the evolution of the low cycle fatigue life can be reached, and this is determined by a combination of material ductility and microstructural transformations. A second characteristic with effect on low cycle fatigue life is the very high strain rate. The transition from the maximum to minimum and vice versa in the axial and shear strains is almost instantaneous. A recent study on structural steel, [17], has shown that yield strength and strain hardening exponent increases with increasing the strain rate. Also, increasing the strain amplitudes cause decrease of the strain rate sensitivity.

Loading Path II is easier to achieve experimentally and probably the most often used in experimental programs that generate non-proportional square loadings. It is characterized by constant strain rates of both axial and shear strains.

Loading Path III shows interest through the sinusoidal variation law of the shear strain overlapped over the axial strain maintained constantly for a half-cycle. Sinusoidal variation involves a variable strain rate of the shear strain. 


\section{Conclusion}

Multiaxial fatigue loadings continuously generate non-proportional loads with significant effects on component durability. Current approaches on fatigue life predictions are cyclebased methods, but evolution of fatigue damage within a loading cycle is also important. Time dependent effects or stress relaxation are factors that may occur during a loading cycle and requires attention. In this paper, four non-proportional square loadings are analysed for the severity of non-proportionality. Two methods were used to analyse the non-proportional factor, proving that both can be sensitive to different variations of axial and shear strains. Also, the principal strain based method has found a higher non-proportional factor compared to non-proportionality induced fatigue damage method.

This study requires a further analysis of stress response and respectively experimental validation.

\section{Acknowledgement}

This study is supported by the project grant FADAMES no. 792652, funded by Marie Curie Individual Fellowship Program from Horizon 2020, European Commission.

\section{References}

1. K. Kanazawa, K.J. Miller, M.W. Brown, Low-cycle fatigue under out-of-phase loading conditions, Transactions of the ASME, Journal of Engineering Materials and Technology, pp. 222-228, 1977;

2. K. Kanazawa, K.J. Miller, M.W. Brown, Cyclic deformation of $1 \% \mathrm{Cr}-\mathrm{Mo}-\mathrm{V}$ steel under out-of-phase loads, Fatigue of Engineering Materials and Structures, vol. 2, pp. 217-228, 1979 ;

3. M.W. Brown, K.J. Miller, Biaxial cyclic deformation behaviour of steels, Fatigue of Engineering Materials and Structures, vol. 1, pp. 93-106, 1979 ;

4. J. A. Bannantine, D.F. Socie, Observations of cracking behavior in tension and torsion low cycle fatigue, Low Cycle Fatigue, ASTM STP 942, H.D. Solomon, G.R. Halford, L.R. Kaisand, B.N. Leis, ASTM, Philadelphia, pp. 899-921, 1988 ;

5. D. Socie, Multiaxial fatigue damage models, Journal of Engineering Materials and Technology, vol. 109, pp. 293-298, 1987 ;

6. T. Itoh, M. Sakane, M. Ohnami, D.F. Socie, Nonproportional low cycle fatigue criterion for type 304 stainless steel, Journal of Engineering Materials and Technology, vol. 117, pp. 285-292, 1995 ;

7. T. Itoh, M. Sakane, K. Ohsuga, Multiaxial low cycle fatigue life under non-proportional loading, International Journal of Pressure Vessels and Piping, vol. 110, pp. 50-56, 2013 ;

8. F. Ogawa, T. Itoh, T. Yamamoto, Evaluation of multiaxial low cycle fatigue cracks in Sn-8Zn-3Bi solder under non-proportional loading, International Journal of Fatigue, vol. 110, pp. 215-224, 2018 ;

9. N. Shamsaei, A. Fatemi, D.F. Socie, Multiaxial fatigue evaluation using discriminating strain paths, International Journal of Fatigue, vol. 33, pp. 597-609, 2011 ;

10. N. Shamsaei, A. Fatemi, D.F. Socie, Multiaxial cyclic deformation and non-proportional hardening employing discriminating load paths, International Journal of Plasticity, vol. 26, pp. 1680-1701, 2010 ; 
11. M. de Freitas, B. Li, J.L.T. Santos, A numerical approach for high-cycle fatigue life prediction with multiaxial loading, Multiaxial Fatigue and Deformation : Testing and Prediction, ASTM STP 1387, pp. 139-156, 2000 ;

12. $\mathrm{H}$. Wu, An empirical non-proportional cyclic plasticity approach under multiaxial lowcycle fatigue loading, International Journal of Mechanical Sciences, vols. 142-143, pp. 66-73, 2018 ;

13. J. Mei, P. Dong, A new path-dependent fatigue damage model for non-proportional multi-axial loading, International Journal of Fatigue, vol. 90, pp. 210-221, 2016 ;

14. B. Liu, X. Yan, A new method for studying the effect of multiaxial strain states on low cycle non-proportional fatigue prediction, International Journal of Fatigue, vol. 117, pp. 420-431, 2018 ;

15. M. Nobah, H. Jahed, E. Ibrahim, A. Ince, Load path sensitivity and fatigue life estimation of 30CrNiMo8HH, International Journal of Fatigue, vol. 37, pp. 123-133, 2012 ;

16. S. Ji, C. Liu, Y. Li, S. Shi, X. Chen, Effect of torsional pre-strain on low cycle fatigue performance of 304 stainless steel, Materials Science \& Engineering A, vol. 746, pp. 5057, 2019 ;

17. N-V. Nguyen, T-H. Pham, S-E. Kim, Strain rate sensitivity behavior of a structural steel during low-cycle fatigue investigated using identation, Materials Science \& Engineering A, vol. 744, pp. 490-499, 2019 ; 